HÄFFNER, Hans-Heinrich, SCHMITT, Reinhard, STEINMETZ, Thomas, Neue Forschungen zum frühen Burgenbau

\title{
Olivier Bruand
}

\section{(2) OpenEdition}

1 Journals

Édition électronique

URL : http://journals.openedition.org/ifha/713

DOI : 10.4000/ifha.713

ISSN : 2198-8943

Éditeur

IFRA - Institut franco-allemand (sciences historiques et sociales)

Référence électronique

Olivier Bruand, «HÄFFNER, Hans-Heinrich, SCHMITT, Reinhard, STEINMETZ, Thomas, Neue Forschungen zum frühen Burgenbau », Revue de l'IFHA [En ligne], Date de recension, mis en ligne le 01 janvier 2006, consulté le 22 septembre 2020. URL : http://journals.openedition.org/ifha/713 ; DOI : https://doi.org/10.4000/ifha.713

Ce document a été généré automatiquement le 22 septembre 2020.

(CIFHA 


\title{
HÄFFNER, Hans-Heinrich, SCHMITT, Reinhard, STEINMETZ, Thomas, Neue Forschungen zum frühen Burgenbau
}

\author{
Olivier Bruand
}

En 2003, la Wartburg-Gesellschaft a tenu à Quedlinburg sa onzième session d'études sur les châteaux ; le présent ouvrage n'est autre que l'édition définitive des diverses contributions présentées à cette occasion. L'objet principal des diverses interventions était de cerner les débuts du phénomène châtelain, avec l'apparition des premières fortifications et leur statut, tandis que les exemples étudiés sont principalement choisis dans l'Allemagne moyenne, malgré quelques incursions dans les Alpes suisses ou en Bourgogne. La période prise en compte correspond aux divisions académiques allemandes des Früh- et Hochmittelalter et s'étend de la fin de l'époque mérovingienne au début du XIIe s., ce qui ne va pas sans créer quelques difficultés quand il s'agit de rechercher l'Adelsburg, le château noble ou seigneurial " privé », qui dans les hautes époques est le plus souvent royal. Mais si l'on montre ainsi, de manière involontaire ici, l'absence de pertinence des modèles qui opposent de façon excessive public et privé, le mérite principal de l'ouvrage est d'établir fermement une chronologie solide du phénomène châtelain sur la longue durée, avec l'existence précoce de châteaux qui servent à l'encadrement local dès le haut Moyen Âge dans la partie méridionale, entre les Alpes et la Franconie, et qui gagnent progressivement vers le nord en même temps que les poussées carolingiennes et ottoniennes. Une réserve toutefois, soulignée par les divers auteurs : leurs travaux portent sur l'archéologie du bâti, sur les plans ou les restes des places fortes en pierre le plus souvent, ce qui occulte fort souvent les éventuelles fortifications en terre ou en bois, très nombreuses avant les premières constructions "en dur ", mais qui coexistent aussi comme pôles secondaires concurremment aux châteaux de pierre. Ces constatations des archéologues rejoignent ici les observations des textes et des monnaies qui livrent précocement nombre de castra et de castella qui semblent bien être les prototypes des châteaux. Enfin, cet 
ouvrage livre aussi un certain nombre d'études monographiques sur des forteresses qui peuvent ainsi avoir valeur d'exemple pour mieux appréhender les phénomènes du développement et du rôle des constructions fortifiées.

La partie la plus neuve est la première avec quatre articles qui s'attachent aux premiers châteaux archéologiquement connus dans les Grisons, dans la Hesse carolingienne, dans le nord de la Bavière et en basse Saxe. En étudiant les fortifications des vallées alpines qui relient l'Italie du nord à la zone danubienne, W. MEYER met en évidence les continuités avec le monde antique ainsi que de très intéressants rapprochement avec les sources fiscales et épiscopales connues par le polyptyque de Coire comme par le testament de l'évêque Tello daté de 765. Les premiers châteaux dont il subsiste des traces sont dans la continuité des castra et castella post-romains et déjà ils combinent les fonctions de contrôle et de défense de la région avec celles de l'encadrement administratif des populations. D'origine publique, à l'époque carolingienne, ils sont reconstruits ultérieurement à l'initiative de seigneurs locaux qui en ajoutent de nouveaux sous la forme de tours ou d'églises fortifiées, l'augmentation du nombre des fortifications accompagnant la croissance de la population. N. WAND consacre son étude aux ouvrages édifiés contre les Saxons en Hesse au VIIIe s., à savoir Büraburg, Amöneburg et le Christenberg. Il s'agit d'ouvrages de garnisons stratégiquement placés pour contrôler les routes, dont les aspects techniques, murs, fossés, tours de défense, utilisation de petits plateaux surplombant renvoient aux héritages militaires romains, mais qui sont abandonnés dès le milieu du IXe s., la région étant alors pacifiée, au profit de pôles de contrôle dans les vici des vallées. Toutefois le savoir-faire militaire mis en œuvre dans ces constructions fut directement réemployé dans les forteresses médiévales classiques. P. ETTEL tente une synthèse qui englobe tous les ouvrages connus dans le nord de la Bavière et fait clairement apparaître l'insuffisance de la tradition écrite, qui ne permet de retrouver qu'un nombre infime de places fortes. Là aussi les premiers châteaux apparaissent dès le VIIe s. dans la vallée du Main, avant de connaître un nouvel essor au début du IXe s. sous l'impulsion de la clientèle noble de Fulda ou de l'évêché de Wurtzbourg qui prend le relais de l'autorité impériale, tandis qu'au Xe s. une série d'ouvrages supplémentaires sont érigés pour faire face aux Hongrois. Si certains d'entre eux conservent une allure modeste avec des levées de terres et des palissades, on en connaît aussi comme Bamberg qui sont le siège d'origine des lignages puissants de la région à l'époque ottonienne. Enfin ces forts jouent là aussi un rôle précoce d'encadrement des populations et on ne saurait les réduire à leurs seules fonctions défensives. En conclusion de cette partie, H. W. HEINE recherche les premiers ouvrages de Basse-Saxe, mais le maintien dans la région d'une tradition de construction en bois ainsi que son intégration plus tardive au monde occidental repoussent son étude vers les Xe et XIIe s., avec un obstacle supplémentaire interdisant des conclusions nettes, qui est que ces places plus tardives ont été sans cesse remaniées jusqu'à une époque récente, ce qui rend les sites souvent peu lisibles.

Olivier BRUAND (Université du Maine, Le Mans) 